\title{
Tekkeköy (Samsun) İlçe Merkezinde Karayolu Trafiğinden Kaynaklanan Emisyon Envanterinin Belirlenmesi
}

\author{
Göksel Kaya ${ }^{1, *}$ \\ ${ }^{1}$ Ordu Üniversitesi, Teknik Bilimler Meslek Yüksekokulu, Elektronik ve Otomasyon Bölümü, 52200, Ordu.

\section{Özet}

Bu çalışma kapsamında Tekkeköy ilçe merkezinde 2017 yılında Karayolları Genel Müdürlüğü tarafindan taşıt sayımı yapılan ana karayolunda seyir halindeki taşıtlardan kaynaklanan emisyon miktarları emisyon faktörü, tașıt saylsı ve yol uzunluğu kullanılarak hesaplanmıştır. Emisyon faktörleri, CORINAIR emisyon faktörü veri tabanından hıza bağlı eşitlikler halinde taşıt sinıfi, yakıt türü, emisyon standard ve motor teknolojisine göre uygun olarak seçilmiştir. Taşıt sayılart ve yol uzunluğu T.C. Ulaştırma ve Altyapı Bakanlığı Karayolları Genel Müdürlüğü'nün yayınladığı Devlet Yolları Trafik Hacim Haritası verilerinden alınmıştır. Emisyonlar MATLAB programlama dili kullanılarak 5 kirletici için $\left(\mathrm{CO}, \mathrm{NO}, \mathrm{UOB}, \mathrm{PM}\right.$ ve $\mathrm{SO}_{2}$ ) ayrı ayrı hesaplanmıştır. Her kirletici ve farklı araç türleri için (otomobil, orta yüklü ticari taşıt, otobüs ve kamyon) emisyon karakteristikleri taşıt hızlarına bağlı olarak ortaya çıkarılmıştır. Sonuçlar 2017 yılında Tekkeköy ilçe merkezindeki taşıt sayımı yapılan ana karayolundan atmosfere salınan kirletici miktarlartnın $\mathrm{CO}$ için 13.56 ton, $\mathrm{NO} \mathrm{O}_{x}$ için 150.23 ton, $\mathrm{UOB}$ için 18.33 ton, $\mathrm{PM}$ için 5.01 ton ve $\mathrm{SO}_{2}$ için 0.20 ton olduğunu göstermektedir. Kamyonlar $N O_{x}$ ve PM kirleticileri için sırasıyla \%66,36 ve \%50,3 değerleri ile en büyük paya sahiptir. Otomobiller CO, UOB ve $\mathrm{SO}_{2}$ emisyonlart için sırastyla \%72.32, \%64.81 ve \%50 değerleri ile en büyük paya sahiptir. Kirletici emisyon miktarlarının 70-90 km/h hız aralığında minimum değerleri aldı̆̆ belirlenmiştir.

\section{Anahtar Sözcükler}

Trafik Emisyonları, Emisyon Envanteri, EMEP/CORINAIR, MATLAB, Tekkeköy, Samsun

\section{Determination of the Emission Inventory from Road Transport in the Tekkekoy (Samsun) District Center}

\begin{abstract}
Within the scope of this study, the emission amounts arising from vehicles cruising on the main highway in the Tekkekoy district center in Turkey, where the General Directorate of Highways counted vehicles in 2017, were calculated. The emission amounts were calculated using the emission factor, the number of vehicles and the length of the highway. The emission factors were selected suitably from the CORINAIR emission factor database in the form of velocity-related equations as vehicle class, type of fuel, emission standard and engine technology. The numbers of vehicles and route lengths were obtained from the data of the State Highways Traffic Volume Map published by the General Directorate of Highways of the Turkish Ministry of Transportation and Infrastructure. Emissions were calculated separately for 5 pollutants $\left(\mathrm{CO}, \mathrm{NO}, \mathrm{VOC}, \mathrm{PM}\right.$ and $\left.\mathrm{SO}_{2}\right)$ by using the MATLAB programming language. Emission characteristics for each type of pollutant and for each type of vehicle (automobiles, light-duty commercial vehicles, buses and trucks) were identified depending on vehicle speeds. The results showed that the amounts of pollutants released to the atmosphere on the main highway where vehicle counts were made in the Tekkekoy district center in the year 2017 as 138.56 tons for CO, 150.23 tons for NOx, 18.33 tons for VOC, 5,01 tons for PM and 0.20 tons for $\mathrm{SO}_{2}$. Trucks had the highest share for the pollutants $\mathrm{NO}_{x}$ and $\mathrm{PM}$ respectively as $66.36 \%$ and50,3\%. Passenger cars had the highest share for the pollutants $\mathrm{CO}, \mathrm{VOC}$ and $\mathrm{SO}_{2}$ respectively as $72.32 \%, 64.81 \%$ and $50 \%$. The amounts of pollutant emissions were found to be at their minimum values in the speed range of 70-90 km/h.
\end{abstract}

\section{$\underline{\text { Keywords }}$}

Traffic Emissions, Emission Inventory, EMEP/CORINAIR, MATLAB, Tekkeköy, Samsun

\section{Giriş}

Hava kirliliği, nüfusun artması, kentlerin büyümesi, endüstrinin gelişmesiyle artan oranda ve değișen içerikte etkilerini sürdürmektedir. Lokal bir kaynaktan salınan hava kirleticiler yerel etkiler gösterirken, kent merkezlerinde enerji tüketimi, fosil yakıt yanması ve motorlu taşıtların artmasıyla hava kalitesinin bozulmasına neden olmaktadır. Mevcut bilgilere göre dünyanın çeşitli bölgeleri arasındaki önemli farklılıklara rağmen, trafik (\%25) şehirlerin hava kirliliğine katkıda bulunan önemli kaynaklardan biri olmuştur (Liu vd. 2018; Pearson 2019; Bouarar vd. 2019; Ganzenmüller vd. 2019). 
Son yıllarda tüm dünyada alınan önlemlerle hava kirliliğine neden olan kirleticiler azalma eğilimi göstermektedir ancak, özellikle kentsel nüfus hâlâ hava kalitesi standartlarını aşan kirletici miktarlarına maruz kalmaktadır (Aunan vd. 2019; Wang vd. 2019; Zeng vd. 2019; Krecl vd. 2018). Günümüzde kirletici emisyonların sınır değerleri Avrupa Birliği (AB) ülkelerinde Hava Kalitesi Yönergesi 2008/50/EC tarafından tanımlanmaktadır (EC 2008). Egzoz emisyonları konusunda AB ülkelerinde yayımlanan mevzuat ülkemizde de benimsenerek 2009 yılından itibaren uygulanmaya başlanmıştır.

Seyir halindeki taşıtlardan kaynaklı hava kirliliğini kontrol etme yöntemlerinden biri de emisyon envanterlerinin hazırlanarak mevcut emisyonların tanımlanmasıdır (Mimi vd. 2017). Emisyon envanteri, sınırları belirlenmiş herhangi bir bölgede, hava kirletici kaynaklardan belli bir zaman aralığında atmosfere verilen kirleticilerin listesi, miktarı ve bunların toplam kirlilik içindeki paylarını gösteren bilgiler olarak tanımlanmaktadır (Ma vd. 2018). Literatür incelendiğinde emisyon envanterleri hazırlanırken genellikle kent merkezindeki bir veya birkaç karayoluna yoğunlaşıldı ̆̆ı, seçilen karayolları üzerinde taşıt sayımlarının otomatik sayım cihazları veya kamera sistemi ile yapıldı ̆̆ı, emisyonların literatürdeki emisyon faktörleri ile belirlendiği ve özel dağıtım modelleri kullanılarak karayolu yakınlarındaki atmosferik dağılım hesaplarının yapıldığı görülmektedir (Lonati vd. 2005; Niemeier 2003; Saija ve Romano 2002).

İçten yanmalı motorlardan atmosfere salınan kirletici emisyonları motorun 1sınmasına kadar geçen sürede atılan emisyonlar, motor 1sındıktan sonra oluşan sıcak egzoz emisyonları ve karbüratörden ve yakıt deposundan yakıtın buharlaşması ile oluşan emisyonlar olarak sınıflandırmak mümkündür (Ergeneman vd. 1998). Motorlu taşıtlardan kaynaklı kirleticilerin büyük çoğunluğunu oluşturan egzoz gazlarının bileşiminde ana kirletici olarak yanmamış hidrokarbonlar, kısmen yanmış hidrokarbonlar $(\mathrm{HC})$, karbon monoksit $(\mathrm{CO})$, azot oksitler $\left(\mathrm{NO}_{\mathrm{x}}\right)$, kükürt dioksit $\left(\mathrm{SO}_{2}\right)$, kurşun bileşikleri ve partikül madde (PM10) sayılabilir (Alvanchi vd. 2019; Seinfeld ve Pandis 2006).

Hava kirliliği raporları Tekkeköy ilçesinde hava ve çevre kirliliğinin her geçen gün daha da arttığını göstermektedir. Hava kirliliği raporlarına göre 2017 ve 2018 değerleri karşılaştırıldığında PM emisyonunda $5 \mu \mathrm{g} / \mathrm{m}^{3}$, CO emisyonunda $321 \mu \mathrm{g} / \mathrm{m}^{3}$ ve $\mathrm{NO}_{2}$ emisyonunda $8 \mu \mathrm{g} / \mathrm{m}^{3}$ 'lük bir artış gözlenirken, $\mathrm{SO}_{2}$ emisyonunda $8 \mu \mathrm{g} / \mathrm{m}^{3}$ 'lük bir azalma meydana gelmiştir. Bu kirliliğin temelinde sanayi kuruluşlarının etkisi oldukça fazladır. Sanayi tesislerinin yanı sıra evlerdeki kömür kullanımı ve trafikteki seyir halindeki araçların saldığı egzoz gazları da diğer nedenler arasında gösterilmektedir (URL-2 2018).

Bu çalışmada, 2017 yılında Tekkeköy ilçe merkezinde T.C. Ulaştırma ve Altyapı Bakanlığı Karayolları Genel Müdürlüğü tarafından taşıt sayımı yapılan 010-16(2) numaralı karayolunda seyir halindeki taşıtlardan kaynaklanan emisyon miktarları emisyon faktörü, taşıt sayısı ve yol uzunluğu kullanılarak hesaplanmıştır. Emisyon faktörleri, CORINAIR emisyon faktörü veri tabanından seçilmiştir. Taşıt sayıları, yol uzunluğu ve hız bilgileri T.C. Ulaştırma Bakanlığı Karayolları Genel Müdürlüğü'nün 2017 yılı için yayınladığı Devlet Yolları Trafik Hacim Haritası verilerinden alınmıştır. Emisyonlar MATLAB programlama dili kullanılarak 5 kirletici için (karbon monoksit (CO), azot oksitler $\left(\mathrm{NO}_{\mathrm{x}}\right)$, uçucu organik bileşikler (UOB), partikül madde $(\mathrm{PM})$ ve kükürt dioksit $\left(\mathrm{SO}_{2}\right)$ ) ayrı ayrı hesaplanmıştır. Çalışma kapsamında taşıt motorlarının ilk çalıştırılması ile termostat açıldıktan sonraki sürüşte ortaya çıkan sıcak emisyonlar hesaplanmış, termostatın açılmaya başladığı ana kadar meydana gelen soğuk emisyonlar ve buharlaşma yolu ile ortaya çıkan emisyonlar veri eksikliğinden dolayı hesaplanmamıştır. Ayrıca Karayolları Genel Müdürlüğü tarafından motosiklet sayımı yapılmadığından bu tip araçlardan kaynaklı emisyonlar çalışmaya dahil edilmemiştir.

\section{Materyal ve Yöntem}

\section{1. Çalışma Alanı}

Karadeniz Bölgesi’nin, Orta Karadeniz Bölümünde bulunan Tekkeköy İlçesi, Atakum, İlkadım ve Canik'le birlikte Samsun İlinin 4 merkez ilçesinden biridir. Samsun - Ordu karayolu (D010) güzergâhında yaklaşık olarak 36² $21^{\prime} 30^{\prime \prime}$ $36^{\circ} 35^{\prime} 30^{\prime \prime}$ doğu boylamları ile $41^{\circ} 01^{\prime} 20^{\prime}$ - $41^{\circ} 15^{\prime} 50^{\prime \prime}$ kuzey enlemleri arasında kalan Tekkeköy; batıdan Canik, doğu ve güneydoğudan Çarşamba, güneyden ise Asarcık ilçeleri ile komşu iken kuzeyinden Karadeniz'e 11,6 km kıyısı bulunmaktadır. Tekkeköy ilçesi en kuzeyinden en güneyine $23 \mathrm{~km}$, en doğusundan en batısına $19 \mathrm{~km}$ uzunluğa sahip olup, yüzölçümü yaklaşık 345 km²'dir. Tekkeköy arazisinin büyük bölümü, morfolojik olarak, Canik Dağlarının kuzey yamaçlarını teşkil eden engebeli sahada yer alırken bir kısmı da 1042 km²'lik yüzölçümüyle Türkiye'nin Karadeniz kıyılarındaki en büyük delta ovası olan Yeşilırmak Deltası üzerinde bulunmaktadır. Şekil 1'de Tekkeköy ilçesinin coğrafi konumu ve yol ağ 1 bilgileri görülmektedir. 


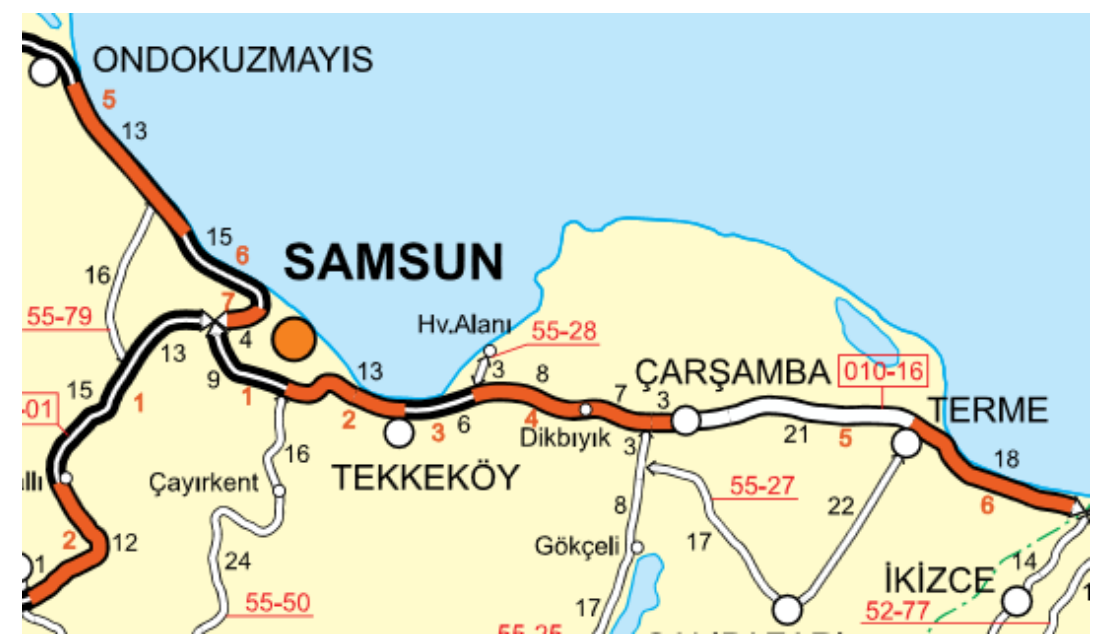

Şekil 1: Tekkeköy ilçesi coğrafi konumu ve yol ağı (KGM 2018)

\subsection{Taşıt Sayımları}

Çalışma kapsamında Tekkeköy ilçe merkezinden geçen ve Karayolları Genel Müdürlüğü tarafından taşıt sayımı yapılan 010-16 (2) numaralı karayolu dikkate alınmıştır. Bu yol sahip oldukları trafik yoğunluğu bakımından ilçe merkezinin hava kalitesini direkt olarak etkileyebilecek niteliktedir. Karayolları Genel Müdürlüğü tarafindan kullanılan taşıt sayım yöntemleri 2 çeşittir (KGM 2018);

a) Otomatik Taşıt Sinıflandırma Sayımları (OTSS1): 2017 yılında 1353 noktada her mevsim en az 7 gün 24 saat süreyle taşınabilir hava basınçlı hortumlu cihazlar kullanılarak yapılan taşıt sınıflandırma sayımlarıdır. Sistem taşıt sınıflandırmalarını, 11 sınıfta aks sayısına ve aks mesafelerine göre gerçekleştirmektedir.

b) Otomatik Taşıt Sinıflandırma Sayımları (OTSS3): Manyetik döngülü cihazlar kullanılarak yapılan sürekli sayım ve sınıflandırma istasyonları olup, Türkiye genelinde 516 noktada kurulmuştur. Sürekli sayım yapılan bu istasyonlardan aylık değişim katsayıları belirlenmekte ve diğer cihazlarla yapılan kısa süreli sayımlardan elde edilen trafik bilgilerinin Yıllık Ortalama Günlük Trafik değerlerine dönüştürülmesinde kullanılmaktadır.

Taşıtlar uzunluklarına göre 9 farklı grupta sınıflandırılmakta olup, taşıt sınıfları 5 farklı grupta değerlendirilmiştir. Manyetik döngülü cihazlardan aynı zamanda taşıt hızlarına ait veriler de toplanmaktadır. Şekil 2'de Tekkeköy ilçesi devlet yolları trafik hacim haritasında taşıt sayımı yapılan nokta ve ölçülen taşıt sayıları görülmektedir. Yıllık ortalama günlük trafik değerleri, hız bilgileri, yol uzunlukları ve sayım türü gibi ayrıntılı bilgiler ise Tablo 1'de görülmektedir.

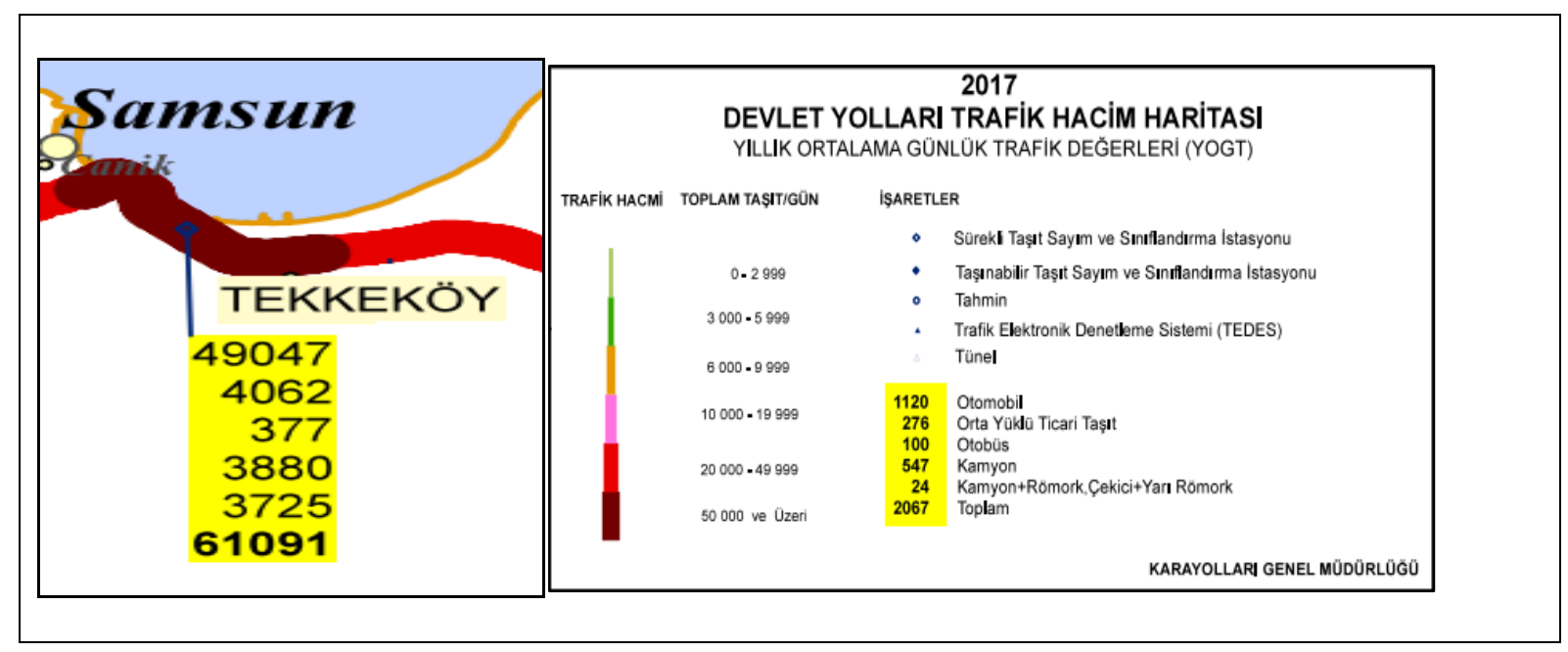

Şekil 2: Devlet yolları trafik hacim haritası (KGM 2018) 
Tablo 1: 2017 yılı Karayolları 7. Bölge Müdürlüğü devlet yolları yıllık ortalama günlük trafik değerleri ve hız bilgileri (KGM 2018)

\begin{tabular}{|c|c|c|}
\hline İLİ/İLÇESİ & \multicolumn{2}{|c|}{ Samsun/Tekkeköy } \\
\hline KKNO* & \multicolumn{2}{|c|}{$010-16$} \\
\hline DÍLİM NO & \multicolumn{2}{|c|}{2} \\
\hline UZUNLUK (km) & \multicolumn{2}{|c|}{13} \\
\hline SAYIM TÜRÜ & \multicolumn{2}{|c|}{ OTSS3 } \\
\hline TOPLAM YOGT* (TAŞIT/GÜN) & \multicolumn{2}{|c|}{61091} \\
\hline \multirow[t]{2}{*}{ OTOMOBİL } & YOGT TAŞIT/GÜN & 49047 \\
\hline & ORT. HIZ (km/h) & 85 \\
\hline \multirow[t]{2}{*}{ ORTA YÜKLÜ TİCARİ TAŞIT } & YOGT TAȘIT/GÜN & 4062 \\
\hline & ORT. HIZ $(\mathbf{k m} / \mathbf{h})$ & 78 \\
\hline \multirow[t]{2}{*}{ OTOBÜS } & YOGT TAŞIT/GÜN & 377 \\
\hline & ORT. HIZ (km/h) & 80 \\
\hline \multirow[t]{2}{*}{ KAMYON } & YOGT TAŞIT/GÜN & 3880 \\
\hline & ORT. HIZ (km/h) & 71 \\
\hline \multirow{2}{*}{$\begin{array}{c}\text { KAMYON+RÖMORK } \\
\text { ÇEKİCI+YARI RÖMORK }\end{array}$} & YOGT TAŞIT/GÜN & 3725 \\
\hline & ORT. HIZ (km/h) & 73 \\
\hline
\end{tabular}

KKNO: Kontrol kesim no, YOGT: Ylllık ortalama günlük taşıt değeri

Karayolları Genel Müdürlüğü tarafından kullanılan taşıt sayım teknolojisinde taşıt sayılarında kullanılan motor teknolojisi ve yakıt türüne ait veriler bulunmamaktadır. Bu nedenle, taşıtların kullandıkları yakıt türlerine göre dağılımları 2013 yılında Kentlerde Hava Kalitesi Değerlendirme Sisteminin Geliştirilmesi Projesi (KENTAIR) kapsamında Samsun ili için hazırlanan "Samsun Hava Kalitesi Değerlendirme Raporu” içerisinden alınmıştır. Taşıtların kullandıkları yakıtlara ve türlerine göre dağılımları Tablo 2'de görülmektedir.

Tablo 2: Taşıtların kullandıkları yakıtlara ve türlerine göre dağılımı (\%) (URL-1 2013)

\begin{tabular}{|c|c|c|c|c|}
\hline & Benzin & Motorin & LPG & Toplam \\
\hline Otomobil & 31.62 & 27.06 & 41.32 & 100 \\
\hline Kamyonet-Minibüs & 4.18 & 93.32 & 2.50 & 100 \\
\hline Kamyon-Otobüs & 2.93 & 97.07 & - & 100 \\
\hline
\end{tabular}

Taşıtların kullandıkları teknolojiye ve türlerine göre dağılımları ise 2013 yılında İstanbul kenti için gerçekleştirilen bir çalışmada kullanılan verilerden temin edilmiştir (Koca ve Elbir 2013). Türkiye'deki araç sayısının \%19'unu oluşturan İstanbul kentinin Türkiye genelini temsil ettiği kabul edilebilir. Taşıtların kullandıkları teknolojiye ve türlerine göre dağılımları Tablo 3'te görülmektedir. Taşıtların kullandıkları teknolojiye ve türlerine göre dağılım oranları dikkate alınırken EURO5 ve EURO6 sınıfındaki araç sayısı ihmal edilmiştir.

Tablo 3: Taşıtların kullandıkları teknolojiye ve türlerine göre dağılımı (Koca ve Elbir 2013)

\begin{tabular}{|c|c|c|c|c|c|c|c|c|c|c|}
\hline & 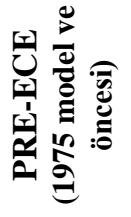 & 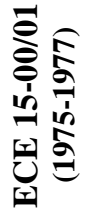 & 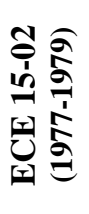 & 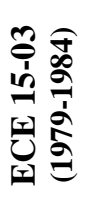 & 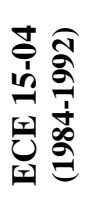 & 方 & 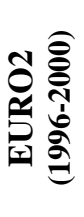 & 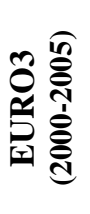 & 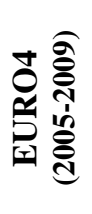 & 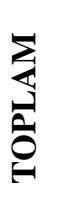 \\
\hline Otomobil & 0.9 & 2 & 0.7 & 1.6 & 11 & 15.4 & 17.6 & 32.1 & 18.7 & 100 \\
\hline Kamyonet-Minibüs & 1.6 & 3.4 & 0.9 & 1.3 & 4.3 & 7.4 & 15.7 & 33.9 & 31.5 & 100 \\
\hline Kamyon-Otobüs & 3.9 & 7.4 & 2.4 & 7 & 13.3 & 11.2 & 16.1 & 20.8 & 17.9 & 100 \\
\hline
\end{tabular}

\subsection{Emisyonların Hesaplanması}

Bu çalışmada emisyon envanterinin hesaplamasında EMEP/CORINAIR metodolojisi temel alınmıştır. Bu metodolojiye göre seyir halindeki motorlu taşıtlardan kaynaklanan emisyonlar Eşitlik 1 yardımıyla hesaplanmaktadır (EEA 2013). Avrupa Çevre Ajansı tarafindan yayımlanan 'EMEP/CORINAIR Emission Inventory Guidebook'un 2016 yılında yeni bir baskısı daha çıkmış ve 2017 ve 2018 yıllarında güncellenmiştir. Ancak bu baskılarda emisyon faktörlerinin taşıt hızlarına bağlı değişimleri verilmediğinden 2013 yılı baskısı dikkate alınmıştır.

$$
E_{i, j, k}=N_{j} \cdot M_{j, k} \cdot e_{i, j, k}
$$


Burada; $i$ (kirleticiler): $\mathrm{CO}, \mathrm{UOB}, \mathrm{NO}_{\mathrm{X}}, \mathrm{SO}_{2}$ ve $\mathrm{PM}, j$ (taşıt sınıfları): Yakıt türü ve üretim yılı, $k$ (yol sınıfi): Şehir içi, şehir dışı ve otoban, $E_{i}$ : Kirletici emisyon miktarı(ton/yıl), $N_{j}$ : Taşıt sayıları (j: üretim yılına bağlı sınıfına göre), $M_{j, k}$ : Taşıtların yaptığı kilometre (j: yol tipi ve k: taşıt sınıflarına göre), $e_{i, j, k}$ : Emisyon faktörü [g/km] (kirleticiler, taşıt sınıfları, yol sınıfına göre)'dir.

Çalışmada yüzlerce farklı emisyon faktörü eşitliği kullanılmıştır. Eşitlik 2'de benzin yakıtı kullanan Euro 4 sınıfı otomobiller için NOx emisyon faktörü örnek olarak verilmiştir.

$$
E F=\left(0.106-1.58 \cdot 10^{-2} \cdot V+7 \cdot 10 \cdot 10^{-6} \cdot V^{2}\right)
$$

Burada; $E F$ : $\mathrm{NO}_{\mathrm{X}}$ emisyon faktörü $(\mathrm{g} / \mathrm{km}), V$ : Taşıt hızı $(\mathrm{km} / \mathrm{saat})$ 'dır. Her kirletici için toplam emisyonlar emisyon faktörlerini kullanarak MATLAB programlama dilinde yazılan bir program ile hesaplanmıştır. Program sadece taşıt sayıları, hızları ve yol uzunluklarının girilmesiyle tüm emisyon miktarlarını hesaplamaya olanak sağlayacak şekilde yazılmıştır. Bu özelliği ile ülkemiz genelinde herhangi bir yere rahatlıkla uygulanabilecek niteliktedir.

\section{Bulgu ve Sonuçlar}

Bu çalışma kapsamında Tekkeköy ilçesi merkezinde Karayolları Genel Müdürlügü tarafından taşıt sayımı yapılan 010 16 (2) numaralı ana karayolunda seyir halindeki taşıtlardan kaynaklı emisyon miktarları hesaplanmıştır. Yıllık ortalama emisyon miktarları ortalama taşı hızları için hesaplanmış ve emisyon karakteristikleri taşıt hızlarının 10-100 km/h arasında değişimi ile belirlenmiştir. İlgili karayolunda günlük 61091 taşıtın seyir halinde olduğu görülmektedir. Taşıtların türlerine göre dağılımlar incelendiğinde otomobillerin \%80.3 ile en fazla dağılıma sahip olduğu görülmektedir. Bunu, $\% 12.45$ ile kamyonlar, \%6.64 ile orta yüklü ticari taşıtlar ve \%0.61 ile otobüsler takip etmektedir. İlgili güzergahta taşıtların hızlarını azaltacak kavşak ve sinyalizasyon sistemi bulunmamaktadır.

Çalışmada emisyonlar taşıt sayıları, ortalama taşıt hızları ve CORINAIR emisyon faktörü veri tabanından seçilen emisyon faktörleri kullanılarak hesaplanmıştır. Emisyonlar karbon monoksit (CO), azot oksitler $\left(\mathrm{NO}_{\mathrm{x}}\right)$, uçucu organik bileşikler (UOB), partikül madde (PM) ve kükürt dioksit $\left(\mathrm{SO}_{2}\right)$ için ayrı ayrı hesaplanmıştır. Tablo 1'de verilen ortalama taşıt hızları için taşıt sayımı yapılan karayolundan kaynaklı yıllık toplam emisyon miktarları Tablo 4 'te görülmektedir.

Tablo 4: Tekkeköy ilçe merkezinde taşıt sayımı yapılan ana karayolundan kaynaklanan yılık toplam emisyon miktarları

\begin{tabular}{|c|c|c|}
\hline İLİ/İLÇESİ & \multicolumn{2}{|c|}{ Samsun/Tekkeköy } \\
\hline KKNO & \multicolumn{2}{|c|}{$010-16$} \\
\hline DÍLIM NO & \multicolumn{2}{|c|}{2} \\
\hline UZUNLUK (km) & \multicolumn{2}{|c|}{13} \\
\hline SAYIM TÜRÜ & \multicolumn{2}{|c|}{ OTSS3 } \\
\hline TOPLAM YOGT (TAŞIT/GÜN) & \multicolumn{2}{|c|}{61091} \\
\hline \multirow{5}{*}{$\begin{array}{l}\text { OTOMOBIL } \\
\text { (ton/yıl) }\end{array}$} & $\mathrm{CO}$ & 100.2 \\
\hline & NO $_{\mathrm{x}}$ & 42.52 \\
\hline & UOB & 11.88 \\
\hline & PM & 1.96 \\
\hline & $\mathrm{SO}_{2}$ & 0.1 \\
\hline \multirow{5}{*}{$\begin{array}{c}\text { ORTA YÜKLÜ TİCARİ TAŞIT } \\
\text { (ton/yll) }\end{array}$} & $\mathrm{CO}$ & 3.53 \\
\hline & NO $_{\mathrm{x}}$ & 2.59 \\
\hline & UOB & 0.45 \\
\hline & PM & 0.37 \\
\hline & $\mathrm{SO}_{2}$ & 0.007 \\
\hline \multirow{5}{*}{$\begin{array}{c}\text { OTOBÜS } \\
\text { (ton/yil) }\end{array}$} & $\mathrm{CO}$ & 0.99 \\
\hline & NO $_{\mathbf{x}}$ & 5.42 \\
\hline & UOB & 0.27 \\
\hline & PM & 0.16 \\
\hline & $\mathrm{SO}_{2}$ & 0.004 \\
\hline \multirow{5}{*}{$\begin{array}{c}\text { KAMYON } \\
\text { (ton/yıl) }\end{array}$} & $\mathrm{CO}$ & 33.84 \\
\hline & $\mathrm{NO}_{\mathbf{x}}$ & 99.7 \\
\hline & UOB & 5.73 \\
\hline & PM & 2.52 \\
\hline & $\mathrm{SO}_{2}$ & 0.09 \\
\hline \multirow{5}{*}{$\begin{array}{c}\text { TOPLAM } \\
\text { (ton/yil) }\end{array}$} & $\mathrm{CO}$ & $\mathbf{1 3 8 . 5 6}$ \\
\hline & $\mathrm{NO}_{\mathrm{x}}$ & 150.23 \\
\hline & UOB & 18.33 \\
\hline & PM & 5.01 \\
\hline & $\mathrm{SO}_{2}$ & $\mathbf{0 . 2 0}$ \\
\hline
\end{tabular}


Tablo 4'de görüldüğü gibi Tekkeköy İlçe merkezinde bulunan 010-16 (2) numaralı karayolundan 2017 yılında çevreye salınan kirletici miktarları $\mathrm{CO}$ için yıllık 138.56 ton, $\mathrm{NO}_{\mathrm{x}}$ için 150.23 ton, $\mathrm{UOB}$ için 18.33 ton, $\mathrm{PM}$ için 5.01 ton ve $\mathrm{SO}_{2}$ için ise 0.20 ton olarak belirlenmiştir.

Şekil 3'de CO emisyonunun çeşitli taşıt türleri için taşıt hızlarına göre değişimi görülmektedir. CO kirleticisi için en büyük payın \%72.32 ile otomobillere ait olduğu belirlenmiştir. Bunu sırasıyla \%24.42 ile kamyonlar, \%2.55 ile orta yüklü ticari taşıtlar ve \%0.71 ile otobüsler takip etmektedir. Şekil 3 'te görüldügü gibi düşük taşıt hızlarında CO emisyonu oldukça yüksek değerler alırken hız artışıyla birlikte değerlerin düştüğü gözlemlenmiştir. Taşıt hızının daha da artırılması durumunda rüzgâr direnci çok arttığından emisyonlar tekrar artış göstermektedir.

Şekil 4'de $\mathrm{NO}_{\mathrm{x}}$ emisyonunun çeşitli taşıt türleri için taşıt hızlarına göre değişimi görülmektedir. $\mathrm{NO}_{\mathrm{x}}$ kirleticisi için en büyük payın \%66.36 ile kamyonlara ait olduğu belirlenmiștir. Bunu sirasıyla \%28.30 ile otomobiller, \%3.62 ile otobüsler ve \%1.72 ile orta yüklü ticari taşıtlar takip etmektedir. Şekil 4'te görüldüğü gibi düşük taşıt hızlarında $\mathrm{NO}_{\mathrm{x}}$ emisyonu oldukça yüksek değerler alırken hız artışıyla birlikte değerlerin düştüğü gözlemlenmiştir.

Şekil 5'de UOB emisyonunun çeşitli taşıt türleri için taşıt hızlarına göre değişimi görülmektedir. UOB kirleticisi için en büyük payın \%64.81 ile otomobillere ait olduğu belirlenmiştir. Bunu sırasıly \%31.26 ile kamyonlar, \%2.46 ile orta yüklü ticari taşıtlar ve \%1.47 ile otobüsler takip etmektedir. Şekil 4'te görüldüğü gibi düşük taşıt hızlarında UOB emisyonu yüksek değerler alırken hız artışıyla birlikte değerlerin düştüğü gözlemlenmiştir. Minimum UOB üretiminin yaklaşık $80 \mathrm{~km} / \mathrm{h}$ civarında üretildiği belirlenmiştir.

Şekil 6'da PM emisyonunun çeşitli taşıt türleri için taşıt hızlarına göre değişimi görülmektedir. PM kirleticisi için en büyük payın \%50.3 ile kamyonlara ait olduğu belirlenmiştir. Bunu sırasıyla \%39.12 ile otomobiller, \%7.39 ile orta yüklü ticari taşıtlar ve \%3.19 ile otobüsler takip etmektedir. Şekil 4'te görüldüğü gibi düşük taşıt hızlarında PM emisyonu oldukça yüksek değerler alırken hız artışıyla birlikte değerlerin düştüğü gözlemlenmiştir. Taşıtlardan meydana gelen PM emisyonları hidrokarbon türevi yakıtların yakılmasının yanı sıra lastik, fren ve debriyaj balatalarından da önemli ölçüde kaynaklanmaktadır. Bu çalışmada sadece yakıt miktarı ve hıza dayalı hesaplamalar yapılmış olup harici durumlar göz ardi edilmiştir.

Şekil 7'de $\mathrm{SO}_{2}$ emisyonunun çeşitli taşıt türleri için taşıt hızlarına göre değişimi görülmektedir. $\mathrm{SO}_{2}$ kirleticisi için en büyük payın \%50 ile otomobillere ait olduğu belirlenmiştir. Bunu sırasıyla $\% 45$ ile kamyonlar, $\% 3$ ile orta yüklü ticari taşıtlar ve \%2 ile otobüsler takip etmektedir. Minimum $\mathrm{SO}_{2}$ üretiminin yaklaşık $70 \mathrm{~km} / \mathrm{h}$ civarında üretildiği belirlenmiştir. 


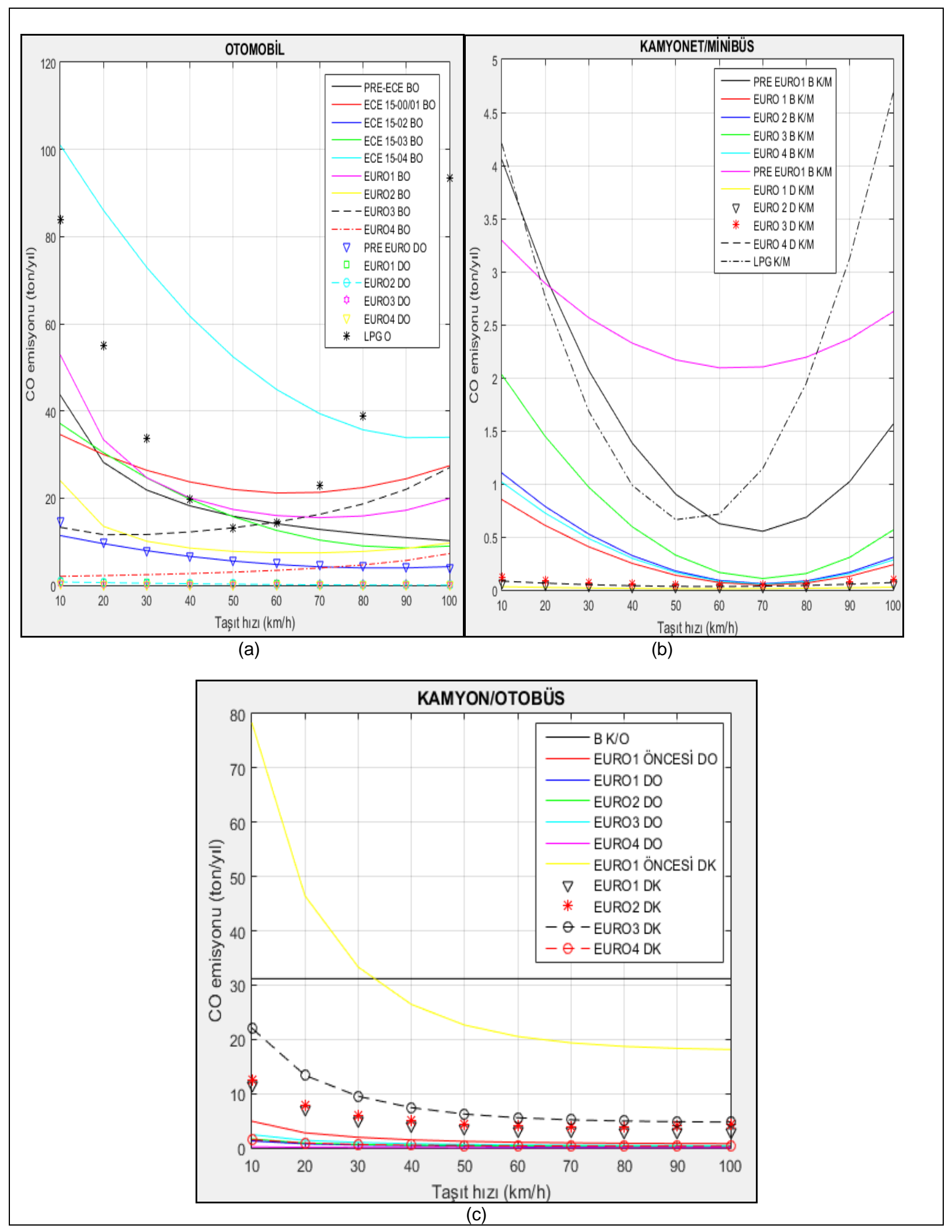

Şekil 3: CO emisyonun taşıt hızlarına göre değişimi a) Otomobil b) Kamyonet/Minibüs c) Kamyon/Otobüs (B: benzinli, D: dizel, O: otomobil, K/M: kamyonet/minibüs, K/O: kamyon/otobüs) 


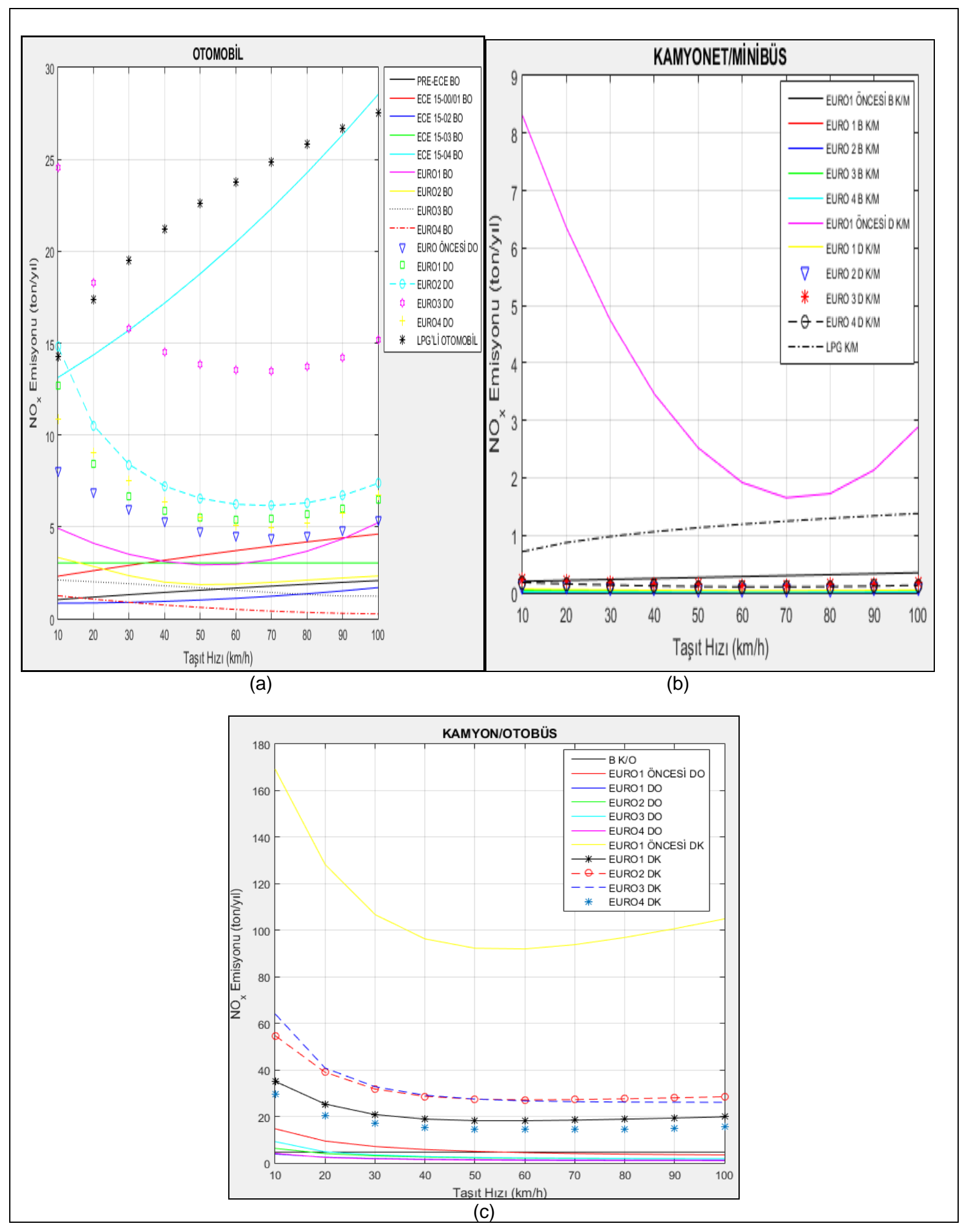

Şekil 4: NOx emisyonun taşıt hızlarına göre değişimi a) Otomobil b) Kamyonet/Minibüs c) Kamyon/Otobüs (B: benzinli, D: dizel, O: otomobil, K/M: kamyonet/minibüs, KNO: kamyon/otobüs) 


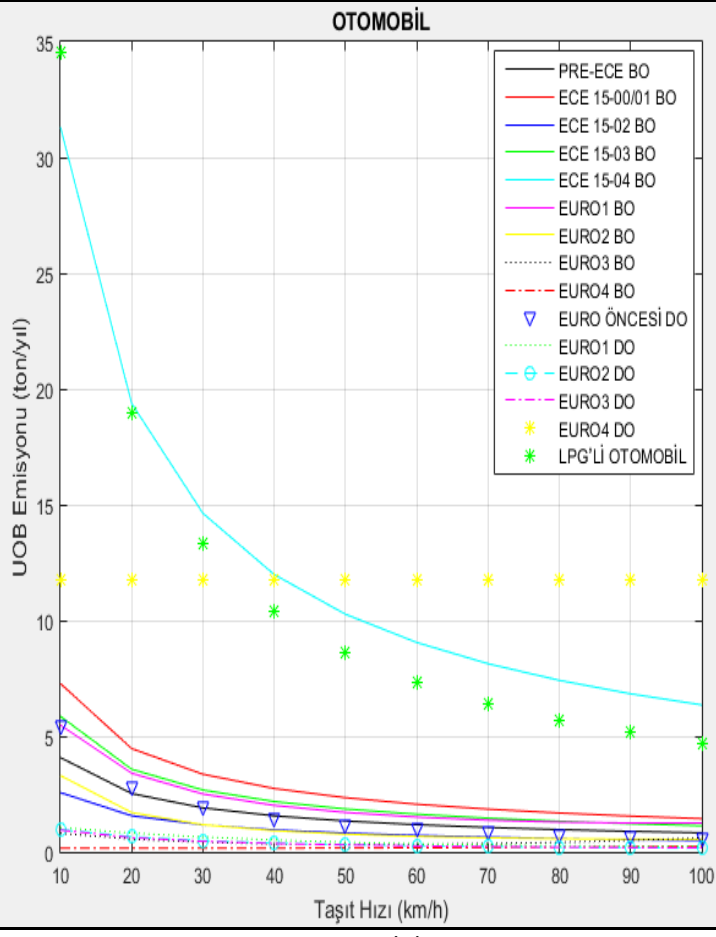

(a)

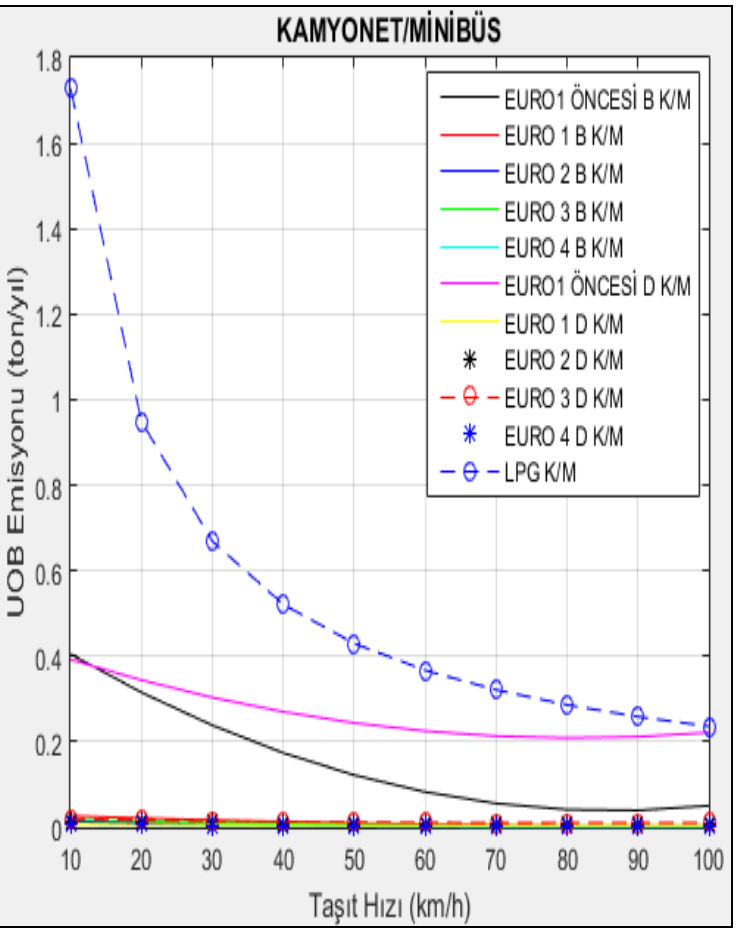

(b)

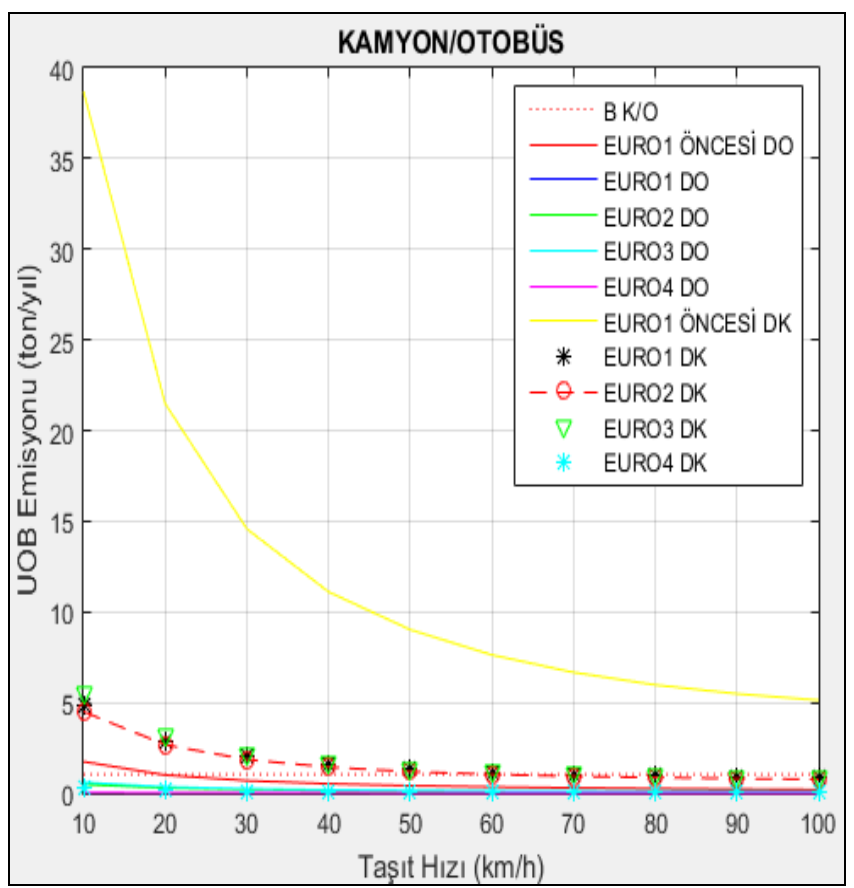

(c)

Şekil 5: UOB emisyonun taşıt hızlarına göre değişimi a) Otomobil b) Kamyonet/Minibüs c) Kamyon/Otobüs (B: benzinli, D: dizel, O: otomobil, K/M: kamyonet/minibüs, K/O: kamyon/otobüs) 


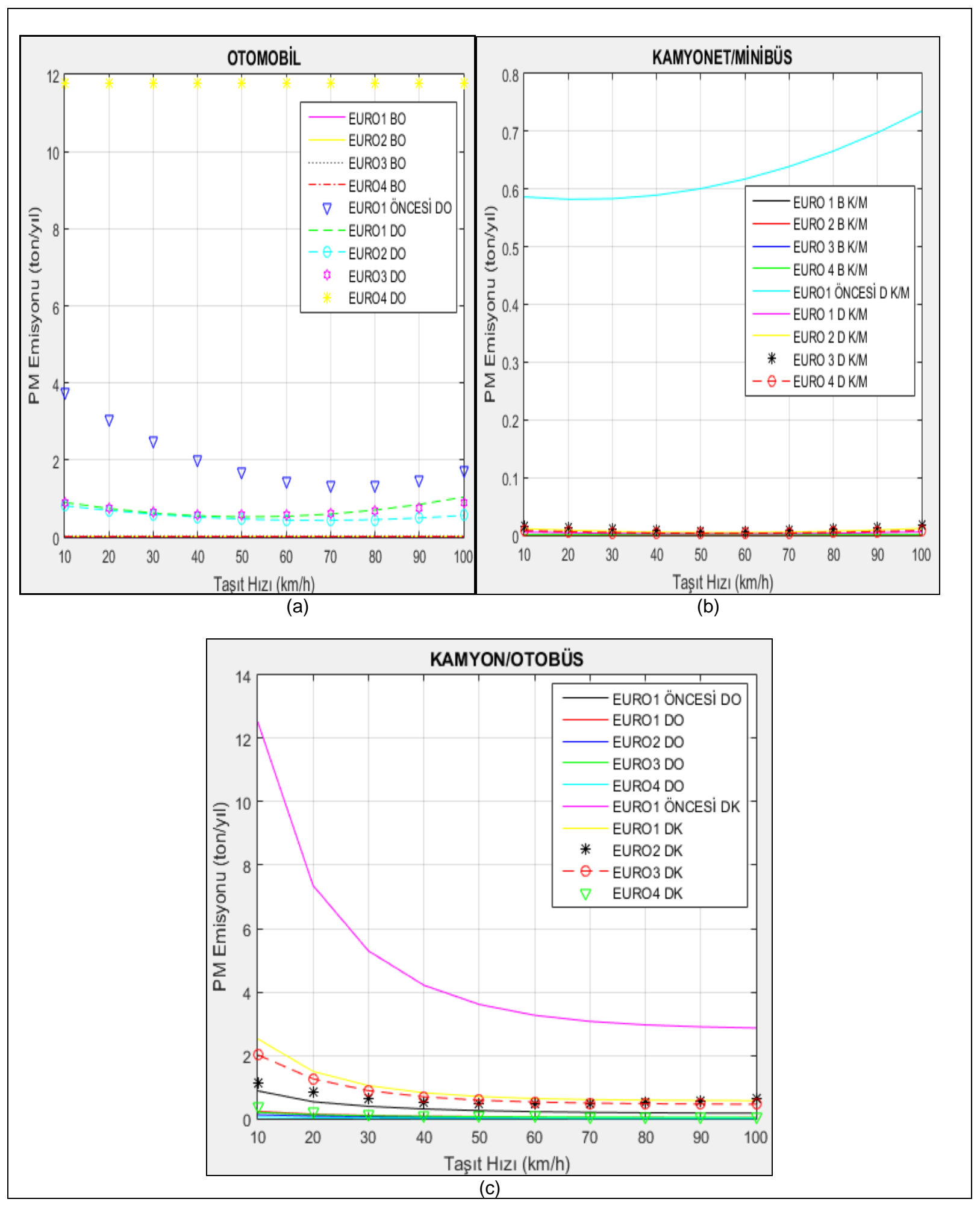

Şekil 6: PM emisyonun taşıt hızlarına göre değişimi a) Otomobil b) Kamyonet/Minibüs c) Kamyon/Otobüs (B: benzinli, D: dizel, O: otomobil, K/M: kamyonet/minibüs, K/O: kamyon/otobüs) 


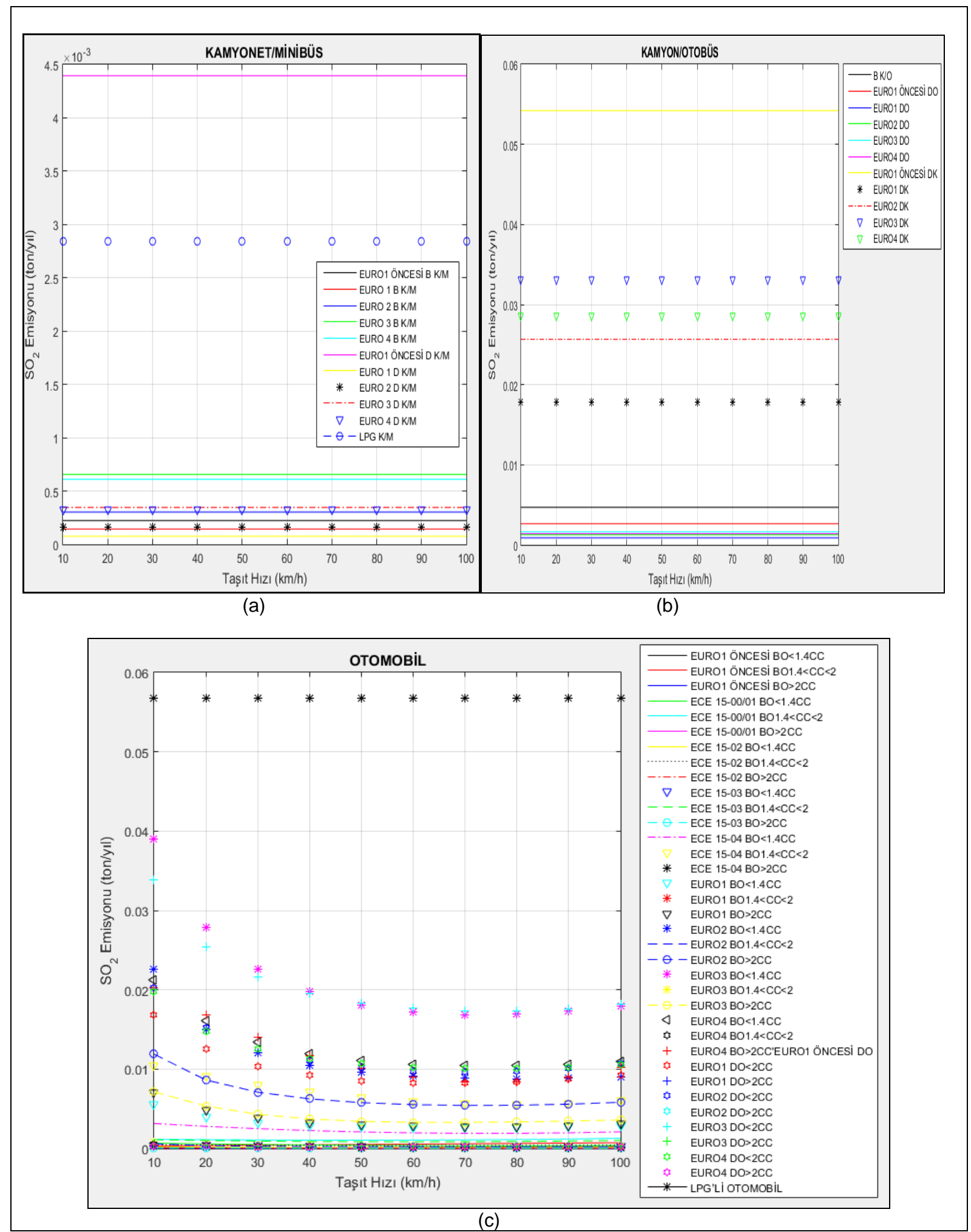

Şekil 7: SOzemisyonun taşıt hızlarına göre değişimi a) Kamyonet/Minibüs b) Kamyon/Otobüs c) Otomobil (B: benzinli, D: dizel, O: otomobil, K/M: kamyonet/minibüs, K/O: kamyon/otobüs, <1.4CC: silindir hacmi 1.4 CC'den küçük taşıtlar, $1.4<C C<2$ : silindir hacmi 1.4 CC ile 2 CC aralığında olan taşıtlar, >2CC: silindir hacmi 2CC'den büyük olan taşıtlar)

Şekil 8'de emisyon sınıflarına göre taşıt türlerinin 5 farklı kirletici türü için toplam emisyon miktarları içindeki yüzdeleri görülmektedir. Euro 1 öncesi taşıt sayısı (8368) Euro 1 sonrası taşıt sayısına (57723) göre oldukça az olmasına rağmen $\mathrm{CO}$ emisyonu üretiminde $\% 25.37, \mathrm{NO}_{\mathrm{x}}$ emisyonu üretiminde $\% 52.55$, PM emisyonu üretiminde \%56.97, UOB emisyonu üretiminde \%60.41 ve $\mathrm{SO}_{2}$ emisyonu üretiminde \%25.37'lik bir paya sahip olduğu belirlenmiştir. 


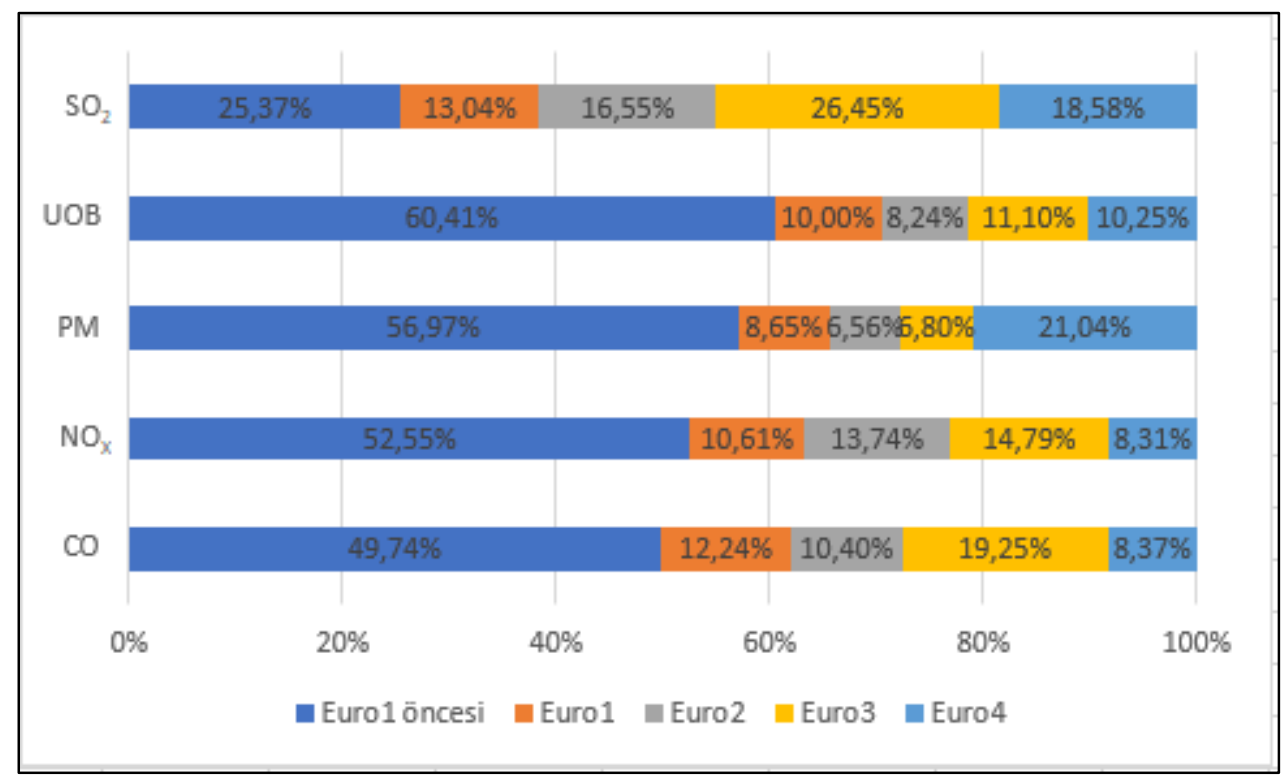

Şekil 8: Emisyon sınıfına göre taşıtların toplam emisyon miktarları içindeki yüzdeleri

Tekkeköy ilçesi için yapılan bu çalışma kapsamında hesaplanan kirletici emisyon miktarları, 2013 yılında Dokuz Eylül Üniversitesi Tınaztepe yerleşkesi içindeki ana karayolu üzerindeki seyir halindeki taşıtlardan kaynaklı emisyon miktarları için yapılan bir çalışma (Koca ve Elbir 2013) ile karşılaştırılmıştır. İlgili çalışmada taşıt sayımları taşıabilir trafik sayım ve sınıflandırma cihazları ile gerçekleştirilmiş ve emisyonlar 5 kirletici için $\left(\mathrm{CO}, \mathrm{NO}_{\mathrm{x}}, \mathrm{UOB}, \mathrm{PM}\right.$ ve $\left.\mathrm{SO}_{2}\right)$ ayrı ayrı hesaplanmıştır. Çalışmada ilgili güzergahta yıllık 1.326 .000 taşıtın seyir halinde olduğu ve yıllık toplam emisyon miktarlarının $\mathrm{CO}$ için yaklaşık 2.8 ton, $\mathrm{NO}_{\mathrm{x}}$ için 1.1 ton, $\mathrm{UOB}$ için 0.4 ton, $\mathrm{PM}$ için 0.05 ton ve $\mathrm{SO}_{2}$ için de 0,15 ton olduğu belirlenmiştir. İlgili çalışmadaki veriler bu çalışmada geliştirilen MATLAB simülasyon programına girildiğinde yıllık toplam emisyon miktarları $\mathrm{CO}$ için yaklaşık 3,1 ton, $\mathrm{NO}_{\mathrm{x}}$ için 4.3 ton, $\mathrm{UOB}$ için 1.46 ton, $\mathrm{PM}$ için 1,18 ton ve $\mathrm{SO}_{2}$ için de 0.033 ton olarak hesaplanmıştır. İlgili çalışmada $\mathrm{CO}, \mathrm{NO}_{\mathrm{x}}$ ve $\mathrm{UOB}$ emisyonlarında en büyük pay otomobillere aitken, $\mathrm{SO}_{2}$ ve $\mathrm{PM}$ emisyonlarında en büyük pay otobüs ve kamyonlara aittir. Bu çalışmada ise kamyonlar ve otobüsler $\mathrm{NO}_{x}, \mathrm{PM}$ ve $\mathrm{SO}_{2}$ kirleticileri için en büyük paya sahipken, otomobiller $\mathrm{CO}$ ve UOB emisyonları için en büyük paya sahiptir. Sonuçlar arasındaki küçük farklılıkların ilgili çalışmada emisyon faktörleriyle bu çalışmadaki emisyon faktörlerinin seçimindeki belirsizliklerden ilgili çalışmada taşıt hızlarının ve güzergah uzunluğunun verilmemesinden kaynaklandığı tahmin edilmektedir.

\section{Değerlendirme ve Öneriler}

Bu çalışmada, 2017 yılında Tekkeköy ilçe merkezinden geçen ve T.C. Ulaştırma ve Altyapı Bakanlığı Karayolları Genel Müdürlüğü tarafından taşıt sayımı yapılan 010-16 (2) numaralı karayolunda seyir halindeki taşıtlardan kaynaklanan emisyon miktarları emisyon faktörü, taşıt sayısı ve yol uzunluğu kullanılarak hesaplanmıştır. Emisyonlar MATLAB programlama dili kullanılarak 5 kirletici için $\left(\mathrm{CO}, \mathrm{NO}_{\mathrm{x}}, \mathrm{UOB}, \mathrm{PM}\right.$ ve $\left.\mathrm{SO}_{2}\right)$ ayrı ayrı hesaplanmıştır.

Sonuçlar 2017 yılında Tekkeköy ilçesinde taşıt sayımı yapılan güzergahtan atmosfere salınan kirletici miktarlarının $\mathrm{CO}$ için 138.56 ton, $\mathrm{NO}_{\mathrm{x}}$ için 150.23 ton, $\mathrm{UOB}$ için 18.33 ton, $\mathrm{PM}$ için 5.01 ton ve $\mathrm{SO}_{2}$ için 0.20 ton olduğunu göstermektedir. Kamyonlar $\mathrm{NO}_{\mathrm{x}}$ ve PM kirleticileri için sırasıyla $\% 66.36$ ve $\% 50.3$ değerleri ile en büyük paya sahiptir. Otomobiller $\mathrm{CO}$, UOB ve $\mathrm{SO}_{2}$ emisyonları için sırasıyla \%72.32, \%64.81 ve \%50 değerleri ile en büyük paya sahiptir. Kirletici emisyon miktarlarının 70-90 km/h hız aralığında minimum değerleri aldığı belirlenmiştir.

Türkiye'de 1 Ocak 2011 tarihi itibariyle rafineriden kırsal motorin satışı ve bununla ilgili ithalatlar durdurulmuş ve 1 Nisan 2011 tarihinden itibaren akaryakıt bayilerinde satışı yasaklanmıştır. Böylece otomotiv yakıtlarındaki en yüksek kükürt oranı motorin ve benzinde $10 \mathrm{ppm}$, oto LPG'de ise $50 \mathrm{ppm}$ olarak uygulanmaya başlanmıştır. Bu gelişmenin motorlu taşıtlardan atmosfere salınan kükürt dioksit emisyonunu oldukça düşürdüğü sonucuna varılmıştır.

Türkiye'de emisyon envanterlerinin hesaplanmasında taşıtların kullandıkları yakıt türlerine ve motor teknolojisine göre dağılımlarındaki veri eksikliği büyük bir sorun olarak ortaya çıkmaktadır. Bu nedenle bu tip güncel verilerin literatüre kazandırılması önem arz etmektedir.

Emisyon sonuçları incelendiğinde özellikle düşük motor hızlarında atmosfere salınan kirletici miktarlarının fazlalığı dikkat çekmektedir. Bu nedenle trafikte kavşak ve sinyalizasyon sisteminin geliştirilmesi ve yeşil dalga sisteminin uygulanması bu soruna çözüm getirebilir. 
Özellikle EURO1 öncesi taşıtların oldukça fazla kirliliğe yol açması konusunda yeni araç ve yakıt teknolojilerinin kullanılması, araç bakımlarının eksiksiz yapılması ve motorlu taşıt vergilerinin emisyon değerlerine göre alınması gibi önlemler alınabilir.

\section{Kaynaklar}

Alvanchi A., Rahimi M., Alikhani H., (2019), Air pollution concentration near sensitive urban locations: a missing factor to consider in the grade separation projects, Journal of Cleaner Production, 19, 1-25.

Aunan K., Hansen M.T., Liu Z., Wang S., (2019), The hidden hazard of house hold air pollution in rural China, Environmental Science and Policy, 93, 27-33.

Bouarar I., Brasseur G., Petersen K., Granier C., Fan Q., Wang X., Wang L., Ji D., Liu Z., Xie Y., Gao W., Elguindi N., (2019), Influence of anthropogenic emission inventories on simulations of air quality in China during winter and summer 2010, Atmospheric Environment, 198, 236-256.

EC, (2008), Directive 2008/50/EC of the European Parliament and of the Council of 21 May 2008 on ambient air quality and cleaner air for Europe (OJ L 152, 11.6. 2008), https://eur-lex.europa.eu/legal-content/EN/TXT/PDF/?uri=CELEX:02008L005020150918\&from=EN, [Erişim 4 Ağustos 2019].

EEA, (2013), EMEP/CORINAIR Emission Inventory Guidebook-2013, European Environment Agency, https://www.eea.europa.eu/publications/emep-eea-guidebook-2013/complete-emep-eea-guidebook-2013/view, [Erişim 2 Ağustos 2019].

Ergeneman M., Mutlu M., Kutlar A., Arslan H., (1998), Taşıt Egzozundan Kaynaklanan Kirleticiler, Birsen Yayınevi, İstanbul, 112 ss.

Ganzenmüller R., Pradhan P., Kropp J.P. (2019), Sectoral performance analysis of national greenhouse gas emission inventories by means of neural networks, Science of the Total Environment, 656, 80-89.

KGM, (2018), 2017 Trafik ve Ulaşım Bilgileri, Trafik Güvenliği Dairesi Başkanlığı, Ulaşım Etütleri Şubesi Müdürlüğü, https://www.kgm.gov.tr/SiteCollectionDocuments/KGMdocuments/Istatistikler/TrafikveUlasimBilgileri/17TrafikUlasimBilgileri .pdf, [Erişim 10 Nisan 2019].

Koca H., Elbir T., (2013), Bir üniversite yerleşkesi içinde karayolu trafiğinden kaynaklanan hava kalitesinin belirlenmesi, Hava Kirliliği Araştırmaları Dergisi, 2, 45-54.

Krecl P., Targino A.C., Landi T.P., Ketzel M. (2018), Determination of black carbon, PM2.5, particle number and NOx emission factors from roadside measurement sand their implications for emission inventory development, Atmospheric Environment, 186, 229-240.

Liu Y.H., Ma J.L., Li L., Lin X.F., Xu W.J., Ding H., (2018), A high temporal-spatial vehicle emission inventory based on detailed hourly traffic data in a medium-sized city of China, Environmental Pollution, 236, 324-333.

Lonati G., Giugliano M., Butelli P., Romele L., Tardivo R., (2005), Major chemical components of PM2.5 in Milan (Italy), Atmospheric Environment, 39, 1925-1934.

Ma X., Sha T., Wang J., Jia H., Tian R., (2018), Investigating impact of emission inventories on PM2.5 simulations over North China Plain By WRF-Chem, Atmospheric Environment, 195, 125-140.

Mimi G., ShashaY., Xingke G., Yuanqian X., Nan J., Ruiqin Z., (2017), Refined 2013-based vehicle emission inventory and its spatial and temporal characteristics in Zhengzhou, China, Science of the Total Environment, 599, 1149-1159.

Niemeier D.A., (2003), The impact of incorporating spatial, temporal variability on running stabilized mobile emissions inventories, Atmospheric Environment, 37, 27-37.

Pearson J.K., (2019), European solvent UOB emission inventories based on industry-wide information, Atmospheric Environment, 204, 118-124.

Saija S., Rono D., (2002), A methodology for the estimation of road transport air emissions in urban areas of Italy, Atmospheric Environment, 36, 5377-5388.

Seinfeld J.N., Pandis S.N., (2006), Atmospheric chemistry and physics: From air pollution to climate change, 2nd edition, WileyInterscience, Hoboken, New Jersey, USA, 1232ss.

URL-1, (2013), Samsun Hava Kalitesi Değerlendirme Raporu (KENTAIR Projesi), https://webdosya.csb.gov.tr/db/destek/editör dosya/Samsun Raporu.pdf, [Erişim 4 Ağustos 2019].

URL-2, (2018), Hava Kalitesi Haber Bültenleri, T.C. Çevre ve Şehircilik Bakanlığı, https://ced.csb.gov.tr/hava-kalitesi-haberbultenleri-i-82299, [Erişim 8 Nisan 2019].

Wang X.C., Klemes J.J., Dong X., Fan W., Xu Z., Wang Y., Varbanov P.S., (2019), Air pollution terrain nexus: A review considering energy generation and consumption, Renewable and Sustainable Energy Reviews, 105, 71-85.

Zeng Y., Cao Y., Qiao X., Seyler B.C., Tang Y., (2019), Air pollution reduction in China: Recent success but great challenge for the future, Science of the Total Environment, 663, 329-337. 